REPORT OF THE TREASURER FOR THE YEAR 1914 RECEIPTS.

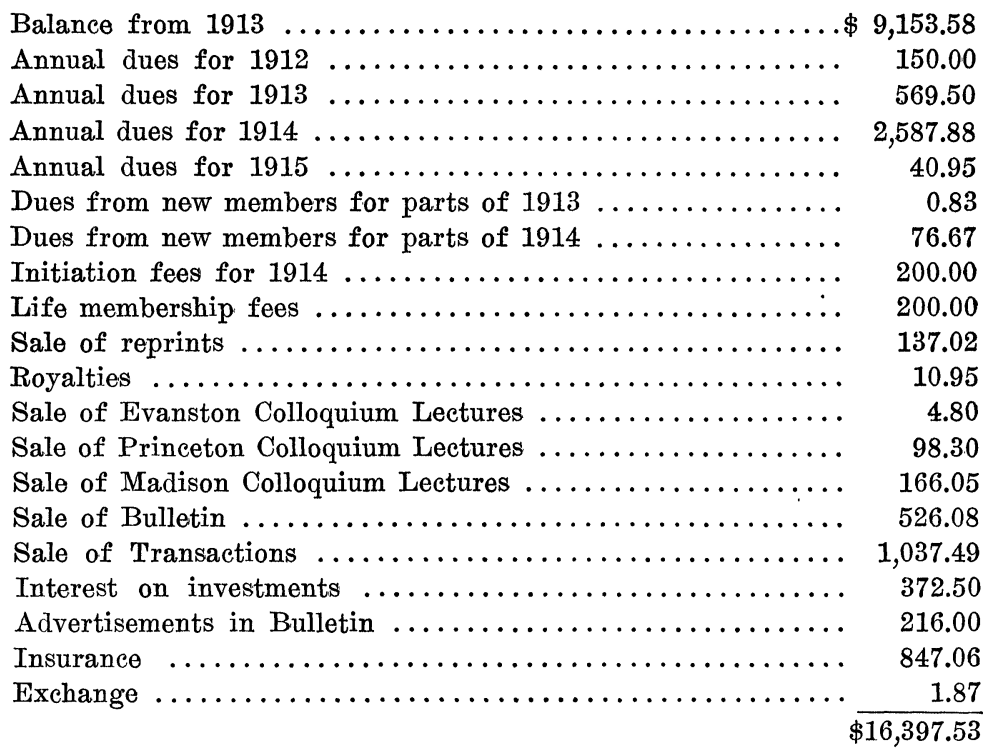

Disbursements

Secretary's Office ....................... 836.23

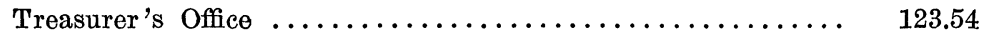

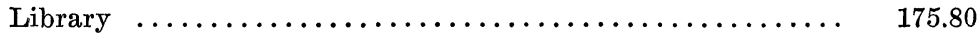

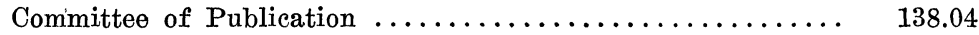

Editorial Committee of Transactions ............... 202.61

Bulletin (ten numbers and index vols. 11-20) $\ldots \ldots \ldots \ldots \ldots 1,829.86$

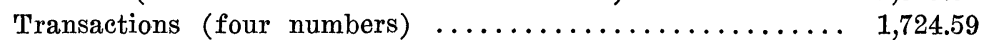

List of Officers and Members ................ 110.00

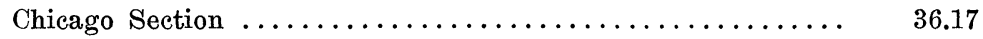

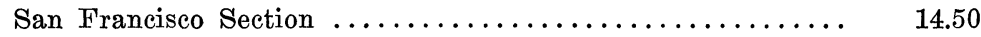

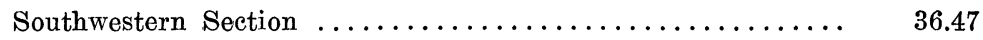

Princeton Colloquium Lectures .................. 9.35

Madison Colloquium Lectures .................. 755.92

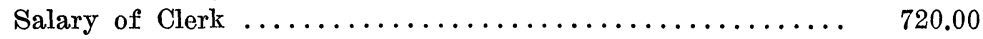

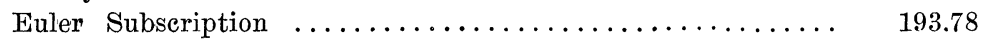

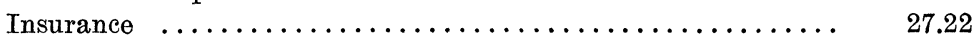

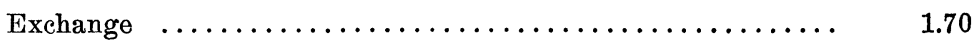


Investments (par value $\$ 8,500.00$ ) $\ldots \ldots \ldots \ldots \ldots \ldots 8,259.50$

Balance in First National Bank (Ithaca) . . . . . 1,202.25 \$9,461.75

$\$ \overline{16,397.53}$

The Life Membership Fund now amounts to $\$ 5,198.85$.

J. H. TANNER,

Treasurer.

ITHACA, N. Y.,

December 23, 1914.

\section{REPORT OF THE AUDITING COMMITTEE}

The undersigned Auditing Committee, appointed by the American Mathematical Society, have this day examined the accounts of the Treasurer, compared them with the vouchers, so far as not destroyed by the fire in the Secretary's office, with the bank balance, and with the list of securities, and find the following to be correct:

Balance from December 23, $1913 \ldots \ldots \ldots \ldots \ldots \ldots \ldots \ldots \ldots$ 9,153.58

Cash receipts since December 23, $1913 \ldots \ldots \ldots \ldots \ldots \ldots \ldots \ldots$ 7,243.95

Balance in First National Bank (Ithaca) . . . . . \$1,202.25

Investments (par value $\$ 8,500.00$ ) ......... 8,259.50

Disbursements since December 23, $1913 \ldots \ldots \ldots \ldots 6,935.78$

NEW YoRK, N. Y.,

H. E. HAWKES,

W. M. Strong, Auditing Committee.

December 23, 1914. 